\title{
El arenero: un recurso didáctico para el desarrollo de la motricidad gruesa en la educación inicial
}

\section{The sandbox as a didactic resource for the development of gross motor}

\section{skills in early childhood education}

1 Verónica Patricia Gutiérrez Tasinchana

https://orcid.org/0000-0002-1522-2840

Universidad Tecnológica Indoamérica, Maestría en Educación Mención Innovación y Liderazgo, Ambato, Ecuador;

veritosguty89@hotmail.com

2 Gissela Alexandra Arroba López

https://orcid.org/0000-0002-7846-6535

Universidad Técnica de Ambato, Facultad de Ciencias Humanas y de la Educación, Carrera de Educación Inicial, Ambato, Ecuador,

ga.arroba@uta.edu.ec

3 Tamara Yajaira Ballesteros Casco (iD) https://orcid.org/ 0000-0002-5962-7962

Universidad Técnica de Ambato, Facultad de Ciencias Humanas y de la Educación,

Carrera de Educación Inicial, Ambato, Ecuador,

ty.ballesteros@uta.edu.ec

$4 \quad$ Irelys Sánchez Fernández

https://orcid.org/0000-0003-4075-6008.

Universidad Técnica de Ambato, Facultad de Ciencias Humanas y de la Educación,

Carrera de Educación Inicial, Ambato, Ecuador,

i.sanchez@uta.edu.ec

\section{Artículo de Investigación Científica y Tecnológica}

Enviado: 24/12/2021

Revisado: 29/12/2021

Aceptado: $12 / 01 / 2022$

Publicado:08/03/2023

DOI: https://doi.org/10.33262/concienciadigital.v6i1.4.1993

Gutiérrez Tasinchana, V. P., Arroba López , G. A., Ballesteros Casco, T. Y., \& Sánchez Fernández, I. (2023). El arenero: un recurso didáctico para el desarrollo de la motricidad gruesa en la educación inicial. ConcienciaDigital, 6(1.4), 179-210. https://doi.org/10.33262/concienciadigital.v6i1.4.1993

CONCIENCIA DIGITAL, es una Revista Multidisciplinar, Trimestral, que se publicará en soporte electrónico tiene como misión contribuir a la formación de profesionales competentes con visión humanística y crítica que sean capaces de exponer sus resultados investigativos y científicos en la misma medida que se promueva mediante su intervención cambios positivos en la sociedad. https://concienciadigital.org

La revista es editada por la Editorial Ciencia Digital (Editorial de prestigio registrada en la Cámara Ecuatoriana de Libro con No de Afiliación 663) www.celibro.org.ec 
Palabras

claves:

educación, matemática, física, específicas, formación

\section{Keywords:}

sandbox,

didactic

resource, gross

motor,

development, cognitive-

motor process.

\section{Resumen}

El Arenero constituye un recurso didáctico para el desarrollo de la motricidad gruesa de los niños en edad inicial potenciando capacidades, habilidades y destrezas que posteriormente se convertían en competencias. Cuánto más pequeño es el niño asimila de mejor manera las concepciones de su contexto por medio de la interiorización de las partes de su cuerpo. La arena es un elemento táctil y estimulante, que, adaptado en el ámbito educativo se transforma en un recurso didáctico para la experimentación de los niños, en donde pueden jugar, socializar, construir, diseñar, ayudando al desarrollo de su motricidad y creatividad. Objetivo. El estudio tiene por objetivo analizar la importancia del uso del arenero en el desarrollo de la motricidad gruesa de los niños. Metodología, se aplica una metodología mixta, es de carácter cualitativo porque los resultados de la investigación fueron ingresados a un análisis de criterios como apoyo al marco teórico, y cuantitativa porque se procesó datos y resultados obtenidos de manera científica en forma numérica. Conclusión. Finalmente se concluye que es importante realizar actividades lúdicas dentro del arenero puesto que éstas coadyuvan al desarrollo de la motricidad gruesa especialmente en la edad inicial pues mediante el juego se estimulan diferentes áreas corporales despertando el interés por parte de los niños/as.

\section{Abstract}

The Sandbox is a didactic resource for the development of gross motor skills in early-age children, enhancing capacities, abilities and skills that would later become competencies. The smaller the child is, the better he assimilates the conceptions of his context through the internalization of the parts of his body. Sand is a tactile and stimulating element, which, adapted in the educational field, becomes a didactic resource for the experimentation of children, where they can play, socialize, build, design, helping the development of their motor skills and creativity. Objective. The study aims to analyze the importance of using the sandbox in the development of children's gross motor skills. Methodology, a mixed methodology is applied, it is qualitative because the results of the research were entered into a criteria analysis to support the theoretical framework, and quantitative because data and results obtained scientifically in a numerical way were processed. 
Conclusion. Finally, it is concluded that it is important to carry out playful activities inside the sandbox since they still contribute to the development of gross motor skills, especially in the initial age, since different body areas are stimulated through play, awakening the interest of children.

\section{Introducción}

Desde pequeños los niños manejan objetos, se trasladan de un lugar a otro, siente curiosidad por descubrir nuevas experiencias, emiten varios sonidos, buscan dar la explicación y posibles soluciones a diferentes problemas del medio, a simple vista parece situaciones que no requieren mayor complicación, pero para ellos significa crecimiento a nivel cognitivo, creativo, motriz y relación con su entorno.

El Ministerio de Educación (2016), tiene como objetivo en el currículo de Educación Inicial, propiciar ambientes, experiencias de aprendizaje e interacciones humanas positivas que fortalezcan el proceso educativo en los niños de 0 a 5 ; por ello uno de los aspectos importantes en el currículo es el uso de materiales concretos como un soporte vital para el adecuado desarrollo del proceso educativo. En el nivel inicial el medio ambiente y la naturaleza, en general, constituyen puntos de apoyo claves para el desarrollo de un trabajo de calidad, por tanto, la creatividad del docente juega un papel muy importante en la concreción del currículo.

Del contexto socioeducativo surge la necesidad por innovar nuevas estrategias metodológicas que aporten de manera significativa el desarrollo motriz y cognitivo de los niños. Los materiales didácticos elaborados previamente y con planificación por parte del docente proporcionan el recurso perfecto para un aprendizaje significativo, desarrollo de la motricidad gruesa y la asociación de nuevas experiencias.

Para Gutiérrez (2019), la etapa comprendida entre los 3 a 5 años se considera la más importante pues es aquí donde se desarrolla el $80 \%$ de las capacidades motoras que permitirán el normal desenvolvimiento en la etapa escolar, esto requiere de la estimulación temprana que se brinde al niño, buena adaptación de recursos y correcta planificación por parte del docente, se debe destacar la importancia del desarrollo motriz grueso para dar paso a la motricidad fina. Esta etapa es la de mayor asimilación y estimulación siendo la base para la formación integral del individuo por medio del desarrollo motriz y no sólo en el desarrollo cognitivo sino social, afectivo y axiológico. El gran reto de los docentes en la actualidad es poner en contexto nuestra sociedad digitalizada y competir a la par con los recursos disponibles y necesarios para lograr el objetivo de desarrollo motriz grueso sin saltar los procesos. 
Según Campo (2009), el estudio del desarrollo humano se ha convertido en una de las principales fuentes de conocimiento, lo que ha posibilitado la construcción de herramientas importantes para profesionales de diversas áreas, puesto que el entendimiento de los factores que influyen en el proceso de cambio permite establecer estrategias para prevenirlos, modificarlos e intervenir sobre ellos de manera oportuna.

A nivel mundial, las instituciones educativas procuran incrementan una serie de recursos didácticos con el objetivo de mejorar la manera de enseñar a los estudiantes y logren adquirir nuevos conocimientos, los esfuerzos por potenciar el nivel motriz y cognitivo en la edad inicial ha hecho que los países a través de organizaciones busquen liderar el ámbito educativo, pues se entiende que la mejor inversión para el desarrollo de un país es la formación integral de las personas, motivo por el cual existe una similitud de pensamiento al momento de preguntarse cuál es la edad más adecuada para poder lograr un aprendizaje significativo en los niños por medio del análisis, la abstracción, inducción, deducción entre otros.

Para Garza (2014), enfocar la labor en los niños pequeños es la inversión más inteligente que un país puede realizar para romper el ciclo de la pobreza, los avances en la neurociencia y los estudios económicos más recientes muestran que las experiencias vividas durante la primera infancia tienen un profundo impacto en el desarrollo del cerebro, motriz y en el aprendizaje posterior.

Para Gutiérrez (2019), el producto de un individuo integral es el resultado de varios componentes que en conjunto forman las habilidades, destrezas y competencias. La buena disposición y profesionalismo de parte del docente también es fundamental para el desarrollo motor de los niños por tal razón es primordial la estimulación en la edad inicial.

La preocupación de los líderes mundiales es sin duda competir en una economía digitalizada donde los principales recursos didácticos se van cambiando por las tecnologías de información y comunicación, dejando de lado la experimentación, investigación, el juego y la socialización por los teléfonos inteligentes, tabletas, ordenadores. A nivel motriz se debe enfocar la atención en aquellas estructuras corporales que deben ser estimuladas acorde a la edad que poseen los niños.

Según la UNICEF (2016), se busca lograr las alianzas estratégicas por medio de la creación de programas educativos para la estimulación temprana y desarrollo motor en los niños: promover la igualdad de oportunidades, el desarrollo integral social, formación axiológica, uso de recursos didácticos adecuados, capacitación del talento humano.

A nivel estatal se pretende actualizar el sistema educativo a través de la generación adecuación de espacios e instalaciones que respondan a las necesidades de los niños, dotar de recursos didácticos más eficientes para la construcción del nuevos 
conocimientos y sobre todo capacitar a los docentes para que ejecuten de mejor manera actividades de aprendizajes significativos útiles para la vida de lo dicentes, todo esto con fin de y lograr una educación de calidad con profesionales comprometidos.

En américa latina la educación escolar se ha caracterizado por la gran variedad de experiencias, así como diversos actores sociales que impulsan la educación. La utilización de los recursos y aprovechamiento de material didáctico proporcionan un aprendizaje que estará presente durante todo el transcurso de la vida del individuo.

Al hablar de los derechos básicos no cubiertos nos referimos a la educación como parte primordial ya que la situación económica de los países latinoamericanos influye de manera notoria en la falta o deterioro de la infraestructura en las instituciones educativas, no existan espacios para organizar los rincones de aprendizaje que son fundamentales en la educación inicial y peor aún recursos didácticos que ayuden a mejorar la motricidad gruesa, siendo aquellos movimientos indispensables que los niños desarrollan en edades de tempranas.

Es importante destacar la educación inicial en sus dos etapas, las mismas que deben ser claras y tratadas en su momento con adecuados espacios y actividades que resultan útiles para el desarrollo evolutivo de los niños; la primera etapa del niño es aquella que va desde los 0 a los 3 años, etapa que considerada de educación maternal, pues los primeros cuidados y estímulos socio afectivos dependen de la familia, una segunda etapa que imparte desde los 4 hasta los 5 años, a esta etapa también se le conoce como educación preescolar, donde los niños desarrollan las destrezas, habilidades motoras que son fundamentales en los primeros años de vida que serán utilizadas a futuro.

En el Ecuador el Ministerio de Educación a partir del año 2012 propuso el proyecto de "reordenamiento de la calidad educativa" para ello el proceso de selección de unidades educativas atravesó por una etapa de acreditación y evaluación, con el objetivo de garantizar la calidez y eficacia educativa. Se realizó la georreferenciación del campo educativo para alcanzar la cobertura y la excelencia en la educación.

Según el Ministerio de Educación (2018), la demanda educativa a nivel nacional es notoria a consecuencia del crecimiento de la población especialmente entre los 3 a 17 años, es por ello que los docentes han ido incrementando en número para satisfacer la demanda escolar, se ha impulsado proyectos con el fin de establecer la planificación correcta con la utilización de recursos didácticos didáctico adecuado a la edad cronológica y física de los niños y niñas, en lo que corresponde al nivel inicial se ha ido estructurando las planificaciones de la mejor manera con el fin de lograr el desarrollo de las destrezas con criterio de desempeño en todos los niños, enfocando un poco más en el conocimiento de su propio cuerpo para llegar al logro del desarrollo de la motricidad gruesa donde está 
inmerso la coordinación de movimiento, el equilibrio que son la base del nivel inicial y luego concretar con el desarrollo de la motricidad fina

El Ministerio de Educación (2014), implementa el Currículo de Educación Inicial 2014 que consta de tres ejes de desarrollo de aprendizaje, siete ámbitos y ciento dieciocho destrezas, específicamente un ámbito corresponde a la expresión corporal y motricidad en el que está inmerso veinte y cinco destrezas, con el objetivo de mejorar la motricidad por medio de los sentidos que se experimenta a través de las sensaciones para lograr una correcta formación de su esquema corporal, de esta manera conseguir movimientos y desplazamientos coordinados, donde se centra en el desarrollo integral, facilitar las experiencias de aprendizaje partiendo del uso de materiales concretos que son de mucha importancia en el nivel inicial.

El arenero es un recurso indispensable para el desarrollo social y cognitivo de los niños, la escasa utilización de este es provocada por el desconocimiento por parte de los docentes a cargo, el desarrollo de la percepción táctil debe ser planificado previamente con la adecuada implementación de materiales acorde a la edad de los niños (López, 2014).

\section{El Arenero}

El arenero es un excelente recurso didáctico que invita a los niños a utilizar la creatividad, la imaginación y sobre todo la experimentación con el contexto que lo rodea. La arena se lo encuentra en el parque o también en la playa sin embargo se puede incorporarlo y adaptarlo en la casa o en la escuela. La curiosidad y el interés son aspectos que despiertan en los niños, los impulsa hacer cosas de manera individual como en grupo, mejora la compresión de conceptos científicos como son: seco, húmedo, liviano, pesado, lleno y vacío (Suárez, 2017).

Las primeras estimulaciones sensoriales son aquellas que se desarrollan al utilizar el arenero. La interacción con objetos que se encuentran en este permite la estimulación de los órganos de los sentidos como son: la vista, oído, olfato, tacto, gusto. Las principales ventajas al utilizar el arenero es el desarrollo de la creatividad y la curiosidad, incluso al experimentar leves accidentes el niño aprende sobre la experiencia adquirida.

El aspecto físico dentro del arenero se estimula y colaboran al desarrollo muscular y óseo, lo que favorecerá notablemente en procesos evolutivos posteriormente, el sistema inmunológico se vuelve más fuerte al momento de contraer enfermedades respiratorias, la conciencia sobre el cuidado del medio ambiente es importante pues al interactuar con la arena, el niño comprende el cuidado de este recurso evitando su contaminación.

Según Alpízar y Alfaro (2019), la socialización es otro de los aspectos que nace y permite al niño interactuar con sus semejantes al colaborar de manera conjunta en la construcción de elementos, la confianza de los padres a sus hijos al momento de permitirles 
desenvolverse y experimentar pues la sobreprotección es un tema que en la actualidad representa uno de los conflictos socioeducativos.

Entre los principales beneficios que ofrece el arenero tenemos: favorece el desarrollo del pensamiento lógico, destrezas, habilidades que se convierten en competencias, la creatividad en el desarrollo de la psicomotricidad gruesa, ésta última es la responsable de diseñar la base evolutiva del ser humano tanto en lo social, cognitivo, la conformación de la personalidad, así como el carácter, la estabilidad emocional entre otras.

Para Orellana (2016), la exploración, planteamiento de problemas, toma de decisiones, fortalecen el crecimiento en las diferentes áreas de desarrollo, constituyen destrezas sociales y emocionales para la comunicación, promueven el desarrollo del lenguaje y enriquecen su vocabulario. El desarrollo motor se fortalece al cargar, sentir y filtrar arena, la expresión creativa de los niños, el efecto de satisfacción al manipular este recurso didáctico.

El rincón de arena es uno de los principales elementos que debe ser usados para dar respuesta a los intereses y necesidades de los niños, al jugar con arena se da respuesta al porqué se halla tan llamativo al dar formas combinadas con agua. Hay que considerar que la arena no importa su estado sea húmeda o seca contribuye a las habilidades finas y gruesas.

Según Valarezo (2016), hay que tomar en cuenta que en la actualidad el valor del juego se está perdiendo, porque la mayor parte de los seres humanos más se enfocan a la tecnología es aquí donde debe intervenir el docente de una manera inteligentes y dar valor a lo que siempre ha sido más importante como es el contacto directo con lo que le rodea, tomando en cuenta que a través del juego forma personas creativas y libres.

El juego y la educación van de la mano porque permite inducir al desarrollo de las capacidades intelectuales a través de las actividades lúdicas que se vaya imponiendo en el transcurso de la vida estudiantil sobre todo en los primeros años, siendo el docente parte fundamental en la formación de cada individuo ya que será el encargado de estructurar actividades innovadoras para la enseñanza de los niños.

\section{Rincón de Arena}

Según Pazmiño (2015), el rincón de arena es un área designada a desarrollar actividades lúdicas y de trabajo, necesaria mente se lo debe adaptar en espacios externos. Es recomendable dentro del aula establecer como un mínimo tres rincones bien definidos. Una característica del rincón de arena es que debe renovarse periódicamente respondiendo a las necesidades para ejercitar las destrezas necesarias acordes a la edad de los niños. Este espacio debe adecuarse con materiales complementarios como cubos, palas, moldes, embudos, coladores, etc. 
Al instante de considerar la utilización del arenero se debe verificar que sus marcos estén en perfecto estado pues aquellas que están deterioradas pueden ser fuente de riesgo para los niños/as. La arena debe ser controlada por la o el docente a cargo y revisar que no exista elementos u objetos cortantes o de otro tipo que genere peligro, se recomienda la arena bien filtrada y cambiada periódicamente, adquirir arena de río o arena de la playa y evitar aquellas que contenga piedra caliza, mármol o sílice que pueden resultar alérgicos para los estudiantes.

Se puede prevenir la contaminación pues los niños/as no son los únicos a quienes les gusta la arena, insectos o animales pueden ser agentes de infección, de igual manera el clima puede ser causante de acumulaciones de agua estancada. En síntesis, el arenero debe ser controlado periódicamente con las debidas precauciones necesarias (Pediatric Environmental Health, 2016).

\section{Recurso Didáctico}

Los recursos didácticos son aquellos materiales que facilitan el proceso de enseñanza aprendizaje tanto para el estudiante como para el docente, pues el puente que se forma durante esta etapa depende del buen uso de herramientas y la aplicación correcta de ésta. La función del docente es el de facilitador y de motivador combinadas con el uso de recursos adecuados. Recursos como el pizarrón es usado para escribir, dibujar y sistematizar contenidos. Los carteles son láminas con imágenes que se caracteriza por su escaso contenido textual, los carteles de bolsillo son un buen recurso para implementar la lectoescritura (Ayoví, 2016).

Los materiales impresos como libros, revistas y periódicos contienen altos contenidos de información importante, las láminas que colaboran a la asimilación del aprendizaje de manera innovadora y divertida, los medios audiovisuales como videos, música, investigaciones, documentales y películas fortalecen y complementan conocimientos previos con los adquiridos, de esta manera se forma en aprendizaje significativo. Los materiales informáticos y multimedia se lo pueden trabajar con edades más avanzadas pues la sociedad actual se manifiesta de forma digitalizada (Gutiérrez, 2019).

El término recurso didáctico tiene dos concepciones diferentes: la primera son aquellos elementos con los que cuenta una unidad educativa, y pueden ser de tipo mobiliario, bibliográfico y audiovisual (Inga, 2016).

Los recursos didácticos son aquellas estrategias que son utilizadas por el docente para facilitar la tarea de procesar y llegar con el conocimiento al estudiante, de ahí la gran responsabilidad de escoger las más idóneas para optimizar el proceso de enseñanza. 
Dentro de los recursos didácticos se debe tomar en cuenta aspectos como: contenidos, actividades de aprendizaje, metodología y evaluación que están dentro de los objetivos y la planificación curricular (Valladares, 2018).

Las principales funciones de los recursos didácticos es dar soporte a la planificación curricular, contribuye a cumplir los objetivos trazados a lo largo de la preparación y sistematización de contenidos. La función motivadora es la encargada de llamar la atención de los estudiantes, despertar su interés para acercarlo más al tema de estudio. La función estructuradora cumple acciones de organización y alternativas de estudio (Urquizo, 2017).

La función didáctica es necesaria para que exista la relación entre materiales, objetivos y contenidos de estudio. La función facilitadora del aprendizaje es prever aquellas acciones que serán previamente planificadas y que se las pueden complementar adecuadamente y de forma concreta (López, 2014).

\section{Estrategias Metodológicas}

Los nuevos retos que enfrenta el campo educativo hacen que el docente se encuentre prevenido y con el uso de herramientas adecuadas para desarrollar actividades que involucre movimientos y por ende el desarrollo motriz. Una estrategia metodológica consiste en la elaboración de un plan académicamente sostenible y sustentable que se transforma en un conjunto de procesos, recursos, caminos para lograr crear el punto que une el conocimiento nuevo con el ya adquirido. En el aula de clases se dicta la materia que aparentan ser simples, sin embargo, para el docente planificador, intrigado por mejorar su accionar educativo y profesional debe considerar los estilos de aprendizaje de los niños (Montenegro, 2016).

En la práctica docente es importante resaltar la planificación de actividades, y ésta puede llegar de diferentes maneras; la conciencia corporal permite entender dónde se ubica el cuerpo y cómo se desenvuelve, la descoordinación en los movimientos o retrasos en el desarrollo motriz evidencia una falencia en su estimulación. Dentro del contexto global el niño en un principio reconoce su cuerpo como un todo y con el tiempo va articulando límites definidos de sus partes.

Según Gutiérrez (2019), las actividades que ayudan al desarrollo motriz no deben ser abordadas de manera aislada de la experiencia de la vida cotidiana, por ejemplo, cuando el niño o niña está sentado con el peso de su cuerpo y cambia de posición al pararse, es el instante preciso donde se desarrolla la conciencia corporal desde el punto de vista más básico.

La planificación conjunta del aprendizaje, iniciativa que debe tomar batuta el docente de aula pues él es componente principal para dar protagonismo a sus estudiantes. La 
improvisación debe quedar de lado y dar paso a un plan estratégico en el aula, proceso que aún requiere atención pues los docentes se dedican a realizar un sinnúmero de actividades de relleno y no se estima el tiempo de la planificación en el hogar. La construcción de gráficos y cuadros es una buena estrategia metodológica siempre y cuando se aplique a temáticas correspondientes, acordes al objeto de estudio (Sánchez, 2016).

Los juegos de roles y de simulación es una estrategia de vital importancia si el objetivo es fomentar la empatía, fortalecer el trabajo en equipo y valorar el individual, practicar los principios y valores. Las estrategias meta cognitivas para aprender a aprender, metodología aplicada en proyectos que hoy en día se pone énfasis desde los años de inicial hasta el bachillerato general unificado.

Los estilos de aprendizaje de cada estudiante se pueden resumir en el siguiente párrafo: El aprendizaje implícito es aquel que se constituye de manera no intencional, el estudiante aprende sin darse cuenta y lo aplica en su diario vivir, generalmente este estilo se lo forma en los primeros años de vida y como ejemplo podemos citar el hablar y caminar. El aprendizaje explícito es aquel en la que el sujeto tiene la intención por conocer algo nuevo o experimentar el conocimiento sobre personas, lugares u objetos, este aprendizaje requiere de la estimulación de los lóbulos prefrontales (Demetrio, 2016).

El aprendizaje asociativo es un tipo de aprendizaje en la que el estudiante responde o relaciona un estímulo frente a un comportamiento determinado. En contraste el no asociado es aquel que se da de forma espontánea, continua y mecánica. El aprendizaje significativo es quizá el más importante pues perdurará para el resto de nuestras vidas y se lo contextualizará según amerite la situación. El aprendizaje cooperativo permite que el conocimiento se de en forma conjunta y no aislada, lo que ocurre en el aprendizaje colaborativo donde mayor énfasis se da al trabajo individual. Es importante resaltar el aprendizaje emocional pues se aprende a controlar nuestras emociones, sentimientos y pensamientos, por lo que es necesario estimularlo para que sea nuestra base de formación como persona íntegra no solo en el aula de clase sino en la vida social (Roa, 2016).

El aprendizaje visual es un tipo de aprendizaje donde el sentido de la vista es el principal protagonista, el individuo comprende de mejor manera por medio de la observación y lo relaciona con su conocimiento adquirido. El aprendizaje experiencial es aquel que se origina con la manipulación directa de objetos, lo desarrollamos en los laboratorios y poniendo en contexto situaciones concretas. En el aprendizaje por descubrimiento el docente desempeña un papel importante pues es el encargado de proporcionar los materiales y herramientas necesarias para que el discente aprenda por sí mismo. El aprendizaje memorístico ayuda a fijar conceptos, pero impide el paso del análisis y síntesis de los conceptos (Rosero, 2018). 


\section{Métodos de Enseñanza}

Es una vía o un camino que se utiliza para lograr el objetivo propuesto de acuerdo con la necesidad observada, el método debe ser escogido con el propósito de llegar a un aprendizaje en los estudiantes. La educación tiene como objetivo que el individuo forme su propia personalidad pues en conjunto es todo aquello que permite fijar las habilidades, destrezas, ordenar ideas los hábitos, costumbres y certezas. En función de cumplir esta meta el proceso educativo encierra diferentes componentes que son la base de su estructura: el docente, los discentes, la comunicación entre los mismos, la interacción en el ámbito institucional, el medio en el que se desarrolla, el contexto socio político y económico, los objetivos trazados, los medios que facilitan la transferencia de la información, las estrategias de asimilación del conocimiento, y lo más importante en el proceso la evaluación de los resultados (Infante, 2016).

En educación inicial el método Montessori es el que utiliza en gran parte ya que proporciona un ambiente planificado, sistemático, donde cada material es previamente diseñado y tiene su razón de ser, es decir cada recurso tiene un objetivo y un fin. El propósito de esta metodología es integrar niños agrupadas en períodos de 3 años promoviendo la socialización, el trabajo en equipo, el respeto y la solidaridad (Gutiérrez, 2019).

El diseño oportuno de ambientes de aprendizaje brinda oportunidades para que el niño se comprometa en un trabajo consciente y capaz de desarrollar su creatividad, en esta área es libre de concentrarse de manera prolongada y al mismo tiempo socializar con sus pares (Yelena, 2016).

El rol principal del docente es el de observador y guía, transmite al niño confianza en todas sus acciones y permite supervisar el normal desarrollo de las actividades. La flexibilidad que se presenta en el currículo integrado permite realizar las adaptaciones necesarias para adecuar el contexto socioeducativo a la realidad requerida (López, 2014).

Es importante que se promueva la independencia del niño con su afán de investigar y llegar a cumplir el proceso de enseñanza aprendizaje, dos aspectos son considerados integrales en la edad comprendida entre los 3 a 4 años que son la libertad y la autodisciplina, la primera relacionada directamente con la exploración y la segunda encaminada a formar la parte axiológica del ser (Little, 2016).

El docente como parte del proceso de enseñanza aprendizaje debe involucrarse en las necesidades evolutivas y características en niños de 3 a 4 años, realizar un seguimiento oportuno y adecuado siempre y cuando surja la necesidad de que el niño se adapte al entorno, de esta manera se construye a sí mismo en relación con el mundo que lo rodea (Gutiérrez, 2019). 
El primer panorama de desarrollo comienza desde el nacimiento hasta los 6 años, y se caracteriza por la mente absorbente, es decir la mente de los niños se asimila a una esponja que abstrae todo lo positivo y negativo sin distinción, he ahí la función del maestro en ayudar a diferenciar las cosas buenas de las malas (Blanck, 2016).

La finalidad del material concreto es promover y estimular las diversas áreas de motricidad y posteriormente el ámbito cognitivo los materiales que se diseñan deben poseer la característica de ser enriquecedores y facilitadores del aprendizaje, más no un distractor que involucre perder el hilo conductor de las actividades planificadas (Gutiérrez, 2019).

La pedagogía de la enseñanza se basa en establecer la diferencia entre el aprendizaje que se da producto de la edad cronológica con la edad mental del niño, es decir identificar el ritmo y estilo de aprendizaje de cada individuo. Resulta indispensable que los intereses de los niños sean protagónicos en todo momento para evitar perder el interés y sostenibilidad de la atención, los padres ejecutan acciones para decidir las alternativas pedagógicas adecuadas para la educación de los niños (Heredia, 2015).

\section{Funciones Básicas}

Para poder definir que son las funciones básicas hay que considerar al ser humano desde su concepción hasta sus últimos días de vida, pues en el transcurso de este periodo desarrolla varios tipos de funcionamientos que pueden ser a nivel físico como psicológico, ambos totalmente diferentes, pero cien por ciento complementarios, es por ello por lo que se debe buscar un equilibrio para tener un óptimo desarrollo. Cuando se presentan dificultades en el desarrollo de estos mecanismos es el momento indicado para dar una estimulación que ayude a superar el problema, tanto a nivel cognitivo tomando en cuenta la edad cronológica y mental de los niños (Ureña, 2014).

Se puede diferenciar dos grandes grupos en las funciones básicas; a nivel mental las cognitivas, y las de desarrollo motriz. En la primera están incluidas la atención, concentración, memoria, lenguaje y las sensopercepciones. En la segunda están implícitas el esquema corporal, lateralidad, direccionalidad, motricidad gruesa, motricidad fina, orientación en el espacio y tiempo, el nudo categorial y el ritmo (Gutiérrez, 2019).

Las funciones básicas cognitivas son procesos o esquemas mentales que permiten a los seres humanos captar información y procesarla, de esta manera el individuo es el protagonista de las diversas situaciones que implica desenvolverse en el contexto que lo rodea. Toda actividad que se realiza implica el uso de las funciones básicas, lo que conlleva al proceso de sinapsis. 
A continuación, se detallan algunas de las funciones más destacadas:

La función básica que permite desarrollar habilidades cognitivas es la atención, se relaciona directamente con el subconsciente y parte a un enfoque subjetivo u objetivo según sea el contexto. Para ponerlo en práctica es necesario la presencia de condiciones físicas y psicológicas, pues la capacidad de concentrar los órganos de los sentidos con la voluntad es un acto que se desarrolla con actividades concretas, exponiendo objetos y figuras, realizar ejercicios correspondientes a números o letras. Es por ello por lo que su evolución depende en gran parte de una buena estimulación en edades tempranas para posterior reflejarlo al momento de realizar actividades que implique mayor esfuerzo (Ramos, 2015).

La concentración corresponde a una parte de la atención en donde el conocimiento ingresa de manera espontánea, es decir a mayor concentración mayor será el aprendizaje, se sugiere realizar actividades utilizando materiales didácticos llamativos, que despierten el interés del estudiante, y con secuencias para la diferenciación de gráficos, dibujos u objetos. Además, permite responder con mayor sutileza y rapidez a los estímulos del medio que se presentan eventualmente sin previo aviso.

La memoria es la capacidad de evocar aquellos conocimientos que se han registrado y almacenado en nuestra memoria. Tiene cuatro funciones que citamos a continuación: la primera corresponde al acto de aprehensión, es decir ingreso del conocimiento donde está presente la atención y la observación a través del sentido de la vista. Segunda es el almacenamiento de dicha información y puede ser a corto, mediano y largo plazo, la tercera función es la reproducción de aquel conocimiento archivado que puede o no ser muy significativo. Por último, la diferenciación que permite distinguir situaciones, conceptos, lugares, hechos históricos, acontecimientos que puntualizan datos precisos (Rodríguez, 2015).

El lenguaje es la función básica que permite la comunicación no solamente oral sino escrita, simbólica, gestual, entre otras, y para poder expresar las ideas, pensamientos y sentimientos es oportuno articular adecuadamente los sonidos y decodificar el mensaje. El desarrollo del lenguaje aparece en los primeros años de vida con sonidos originados en la garganta, después los sonidos labiales y luego la imitación de los sonidos. Para poder leer es indispensable el dominio del lenguaje oral, el proceso de lectura es una contrastación de gráficos, rasgos y sonidos, su adquisición da pasa a la escritura. No puede el niño escribir sin antes dominar la lectura (Cupuerán, 2014).

Las sensaciones son estímulos captados por los órganos de los sentidos, oído, vista, tacto, gusto, olfato y tacto toman el nombre de sensaciones. Cuando uno de los sentidos se ve afectado y hay la condición de capacidades diferentes el proceso de enseñanza 
aprendizaje se complica tanto para el docente como para el estudiante, sin embargo, hay sentidos que se desarrollan con más intensidad a la ausencia de otros (Pinza, 2018).

Las percepciones son un conjunto de respuestas que brinda el organismo frente a estímulos exteriores complementándolo con experiencias concretas, este proceso implica la atención, la sistematización de ideas, la jerarquización, respuestas verbales, motrices, numéricas y gráficas. La percepción auditiva permite reconocer y captar estímulos sonoros, y se la desarrolla a través de la práctica. La conciencia auditiva es la capacidad de reconocer sonidos del medio ambiente, de la flora y fauna entre otros objetos. Por otra parte, la memoria auditiva es la reproducción y evocación de sonidos ya adquiridos (Peña, 2015).

La discriminación auditiva posibilita la detección de fonemas que inician o finalizan con un mismo sonido, este incorpora un prerrequisito para el acto comunicativo. El docente dispondrá de material adecuado para poder estimular adecuadamente el nervio auditivo de sus estudiantes (Gutiérrez, 2019).

La percepción visual permite al niño/a la capacidad de observar los estímulos en su totalidad, coadyuva al discernimiento entre tamaños, colores, formas, posiciones dentro del espacio tiempo. La coordinación óculo manual se desarrolla en esta etapa con la utilización de la pinza digital, es menester trabajar en trazado continuo de líneas horizontales como verticales, el discernimiento de figuras, la constancia en la forma, las relaciones espaciales, la posición en el espacio (Lamar, 2018).

\section{Desarrollo evolutivo del niño}

El desarrollo evolutivo de niño no es otra cosa sino las actividades que se contextualizan con el diario accionar de cada ser a lo largo de su vida. Al mismo tiempo se establece los rangos normales que se deben cumplir transcurridas cierto tiempo, la psicología educativa dice que estudiar al ser humano en todas sus etapas resulta complejo y diverso pues los patrones de comportamiento se ven reflejados e influenciados por factores internos, externos y emocionales. En síntesis, se puede definir al desarrollo evolutivo del niño como un proceso por medio del cual se adquiere habilidades y destrezas indispensables para su normal desenvolvimiento (Ruiz, 2015).

\section{Etapa de 3 a 4 años}

La intuición es parte del período de desarrollo del niño que se caracteriza por tener un pensamiento anterior a la lógica, Piaget asegura que este esquema imita los datos perceptivos del contexto social. A esta edad el niño continúa con el pensamiento egocéntrico, a lo largo de la etapa se aprenden nuevas habilidades (C. Pérez, 2015). 
El dibujo tiene una importancia vital previo a la escritura y que todos los niños pasan por ellas, a partir de los cuatro años el niño tiene una clara noción de lo que es reproducir un dibujo y a los 5 o 6 años sabe dibujar (Gutiérrez, 2019).

El proceso de lectura de manera progresiva se convertirá en un sistema de comunicación para intercambiar ideas, sentimientos y pensamientos, la utilidad de palabras, vocabulario adquirido y la fluidez son características avanzadas del lenguaje (Gutiérrez, 2019).

\section{Desarrollo social}

El juego paralelo permite la socialización entre semejantes, aunque el trabajo colaborativo no se lo asocia todavía, se presenta la rivalidad pues el niño aun es egocéntrico y supone que el entendimiento del mundo solo la ve a través de sus ojos (Gutiérrez, 2019).

El juego es una actividad que resulta divertida para el niño o niña que permite satisfacer las necesidades cognitivas, sociales, educativas y culturales. Es recomendable establecer reglas para su normal desenvolvimiento.

\section{Tipos de juego}

Aquellas actividades que aporten como experiencias significativas por medio del juego y que son relatadas como historias o cuentos pasan de un instante a otro de la realidad a la fantasía, es por ello por lo que la programación de actividades lúdicas es indispensable por parte del docente (M. Pérez, 2016).

\section{Orientación espacial}

Es la capacidad que tienen los niños para poder establecer hechos y elementos situados en el espacio, para poder desarrollarla se debe considerar que en las actividades esté presente las sensaciones y el movimiento. Definiciones como arriba, abajo, adelante, atrás, izquierda, derecha, encima y debajo son elementales para un aprendizaje significativo. Más tarde en la edad adulta se fortalece esta orientación para poder guiarnos en el espacio tiempo y dar lectura a mapas de ubicación geográfica (Medina, 2015).

\section{Orientación temporal}

Es la habilidad que permite situarse en el espacio tiempo, no solo del esquema corporal sino también de objetos concretos. Cuando se hace referencia al tiempo se pueden establecer determinados intervalos para poder indicar un principio y un final. Esta facultad se ve deteriorada cuando se observa la falta de organización, al momento de comparar y contrastar sucesos, y se recomienda trabajar en nociones como noche, día, tarde, ayer, mañana, la próxima semana, el otro año, diferenciar las estaciones del año, las unidades básicas del tiempo entre otras (Arroba, 2018). 


\section{Nudo categorial y ritmo}

El desarrollo evolutivo del niño o niña depende de tres elementos: el tiempo, espacio y el movimiento, sin la interacción armónica de éstos, no se puede hablar de un desarrollo evolutivo normal de los niños. Este nudo categorial va modificándose a raíz que el niño crezca. En los primeros meses de vida del infante se da la impresión del movimiento, entre los tres a seis años se inicia la orientación en el espacio, y a partir de los seis años la orientación en el tiempo, los tres componentes se van relacionando, desarrollando el ritmo en los niños y niñas (Caizaguano, 2015).

\section{Desarrollo motriz}

El desarrollo motor se estima como el conjunto de procedimientos secuenciales y permanentes, por medio de ellos los seres humanos tienen un sinnúmero de habilidades motoras, cada individuo con una en particular. Se he de destacar que el desarrollo motriz no se da de manera aislada sino conjunta y es influenciado por rasgos biológicos y de carácter hereditario, esto no quiere decir que habilidades o destrezas no adquiridas no se puedan desarrollar en un futuro (Gutiérrez, 2019).

La motricidad va organizando y adaptándolo de forma gradual a la edad de 4 a 5 años y está muy ligada a las leyes generales de la maduración del sistema nervioso. Según la ley cefalocaudal el control sobre el movimiento de los miembros superiores es anterior al de los inferiores y de acuerdo con la ley próximo-distal, el control sobre una parte del cuerpo es más tardío cuanto más alejada esté del eje central. De esta forma el niño consigue progresivamente con relación a la ejecución gráfica: el control de la postura, la independencia músculo-brazo, la independencia brazo-mano, la independencia de dedos, la aprehensión de los útiles, la presión sobre los útiles y la coordinación prensión-prensión (Guirado, 2016).

A los 3-4 años actividades como paseos en la barra de equilibrio, atrapara una pelota saltarina, montar una bicicleta, saltar en un pie por lo menos entre 5 a 10 segundos, saltar repetitivamente y subir las escaleras paso a paso, son entre otras tareas a desarrollar por el docente.

A los 4-5 años se pueden realizar actividades como: equilibrio corporal, paseos en barra y por las escaleras, patear la pelota en movimiento, atrapar pelotas grandes y pequeñas con el brazo extendido y lanzarlas. De 5 a 6, equilibrio corporal, saltar, paseos en bicicleta, saltar la cuerda, saltar en un pie diez veces, atrapar balones al ser arrojados, balanceo en el columpio (Universidad Rafael Landívar, 2017). 


\section{Esquema corporal}

El esquema corporal representa la imagen mental del cuerpo, éste se manifiesta cuando se toma consciencia de su estructura, composición y el normal funcionamiento. Conocer nuestro cuerpo permite responder eficazmente ante situaciones que se presentan en el diario vivir, por ende, es vital que en los primeros años escolares aprenda a reconocer el cuerpo como un todo y a la vez de manera individual. Como parte fundamental al esquema corporal el equilibrio lo complementa idealmente y sin ella las personas no podrían realizar actividades como caminar, levantarse. (Muñoz, 2016).

\section{Motricidad}

Es un concepto que se utiliza para coordinar movimientos que realiza un individuo que implica el sistema locomotor que puede ser a nivel fisiológico y neurológico. Podemos citar la motricidad fina y la motricidad gruesa.

\section{Motricidad fina}

La motricidad fina se refiere a todos los movimientos minúsculos que se realiza con las manos o dedos, el producto de ésta depende de una buena estimulación de múltiples actividades como el anudar, abrochar, atornillar, tapar, pelar, coser, cortar. Otra manera de ejercitar es el rasgado, contorneado, el relleno de las figuras (Castelo, 2016).

\section{Lateralidad}

Es la predominancia el momento de utilizar una parte del cuerpo, es decir tanto las extremidades superiores como inferiores están acostumbradas a influir al instante de realizar una tarea, por ejemplo, al momento de escribir o en el instante que se golpea el balón de fútbol. Tradicionalmente se ha cometido un atentado por la utilización de la mano izquierda llegando a ser inutilizada y en algunos casos amarrada para forzar el desarrollo de la mano y por ende pie derecho (Venegas, 2015).

Pero en realidad quien tiene la razón de utilizar uno u otra mano, nadie sabe, es una incertidumbre que en la actualidad se la puede responder de manera indiferente. Primitivamente al cumplimiento de los tres años los niños toman una preferencia o tendencia por utilizar una mano más que la otra. La función docente debe ser la estimulación de ambas lateralidades, pues su beneficio directo es el desarrollo cognitivo tanto el hemisferio izquierdo como el derecho.

Para Andrade (2015), mientras que las personas que utilizan la lateralidad derecha desarrollan el hemisferio izquierdo, las personas que utilizan la lateralidad izquierda desarrollan el hemisferio derecho. Algunos de los ejercicios que se pueden realizar para mejorar la lateralidad es la identificación de los términos derecho e izquierdo, dibujarse 
con tiza en el patio, caminar por línea recta a lo largo de la cancha, jugar a cambiar la mano derecha por la izquierda. Las actividades que se utilicen serán considerando la edad de los niños con un grado de complejidad adecuado para ir incrementando su habilidad.

\section{Direccionalidad}

Como lo detalla Sailema (2018), la direccionalidad está ligada con la lateralidad pues ésta resulta de una proyección consciente del lado derecho e izquierdo. Una vez que el niño y niña haya aprehendido este concepto surge las nociones de orientarse a los lados antes mencionados y aparecen: arriba, abajo, adelante, atrás. Estas nociones se adquieren posterior a la lateralidad y se ven afectadas cuando no se tiene claro cuál es la derecho o izquierda. Para poder desarrollarla se puede señalar objetos con las nociones mencionadas, dibujar en el suelo figuras geométricas, ubicar elementos en diferentes posiciones, construir patrones con diferentes figuras.

\section{Motricidad gruesa}

Según Troya (2015), a diferencia de la motricidad fina la gruesa se refiere a aquellos movimientos grandes o que implica mayor fuerza, éstos son realizados con las extremidades tanto superiores es decir los brazos, como las inferiores las piernas, también se utiliza el tronco de cuerpo para realizar algunas actividades. La motricidad gruesa se desarrolla en primer lugar pues es indispensable para dar paso a la fina sin ella no podríamos caminar, sostenernos, desplazarnos para alcanzar objetos entre otras actividades. El docente puede estimular estos ejercicios en el momento de caminar, marchar, subir y bajar escaleras, bailar, dar saltos, juegos en cancha, el equilibrio a la par se desarrolla y en síntesis el niño y niña se divierte sin conocer que va evolucionando su cuerpo constantemente.

La capacidad motriz gruesa consiste en contraer grupos musculares diferentes de forma independiente, o sea, llevar a cabo movimientos que incluyen a varios segmentos corporales. Para que sea eficaz la coordinación psicomotriz se requiere de una buena integración del esquema corporal, así como de un conocimiento y control del cuerpo. Esta coordinación dinámica exige la capacidad de sincronizar los movimientos de diferentes partes del cuerpo. Por ejemplo, salta, brincar en un pie, sobre llantas etc.

Para Pérez (2015), la motricidad gruesa tiene que ver con los movimientos de posición del cuerpo y la capacidad de mantener el equilibrio. Cuando se habla de motricidad gruesa se entiende aquellas acciones que se realizan de manera armónica lo que da como producto la estimulación en la agilidad, fuerza y velocidad. El ritmo que evoluciona cada niño varía, pero siempre inmerso dentro de parámetros establecidos.

El desarrollo de la motricidad gruesa va en forma cefalocaudal es decir desde el cuello, pasa por el tronco del niño y la cadera, y finalmente termina en las piernas, pasa por las 
siguientes fases. El control de la cabeza: a los dos meses el niño empieza a tener control cefálico es decir ya puede sostener su cabeza. Por ejemplo, cuando el bebé está acostado debe ser capaz de levantar y mover la cabeza. Para esto necesita ir cogiendo fuerza en su cuello y en su espalda, además de hacer uso de las manos

\section{Aspectos de parámetros naturales}

Según Cobo (2015), el control cefálico a los dos meses, es decir cuando el bebé es capaz de levantar y mantener el equilibrio en el cuello, se sienta a los seis meses, el gateo que por lo general comienza a los nueves meses sin considerar el aspecto que no siempre se gatea antes de andar, bipedestación a partir de los diez meses, de ambulación a los doce meses. Los signos de alerta que se debe considerar son: el no control cefálico a los cuatro meses, la sed estación a partir de los nueve, y la marcha al año y medio.

Los principales movimientos musculares incluyen: las piernas, brazos, cabeza, tronco y la espalda, así como también la captación de sensaciones por medio de los órganos de los sentidos, (oído, vista, tacto, gusto y olfato), el objetivo del desarrollo de la motricidad gruesa es la adquisición de habilidades en el área cognitiva y del lenguaje, importantes para la comunicación y transmisión de ideas, propuesta y resolución de conflictos.

\section{Ejercicios para desarrollar la motricidad gruesa}

Para Rosero (2017), principalmente para los niños comprendidos entre edades de 3 a 4 años el mejor ambiente para desarrollar la motricidad gruesa es el rincón de arena con la incorporación de objetos para incentivar la creatividad y la imaginación, el docente puede pedir a sus estudiantes que localicen diferentes partes de su cuerpo como: cabeza, frente, ojos, oídos, boca, cuello, hombros, pecho, cintura, abdomen, cadera, brazos, codo, muñeca, manos, palmas, piernas, rodillas, talón, pies y finalmente los dedos.

Otras actividades que se pueden implementar son: armar rompecabezas del cuerpo humano, subir y bajar las escaleras, dibujar la silueta del cuerpo humano en espacios amplios como el patio, bailar en diferentes ritmos y distintos movimientos, realizar marchas, realizar ejercicios coordinados mientras una mano realiza una acción la otra puede realizar una distinta, los juegos populares, el gato y el ratón, rayuela, imitación de animales, estatuas, escondidas, saltar la soga entre otros.

\section{Motricidad gruesa en niños de 3 a 4 años}

Desde el nacimiento hasta los seis años es importante el desarrollo de habilidades y destrezas que los niños deben adquirir por medio de la correcta estimulación con actividades especialmente lúdicas, que fomenten la destreza cognitiva y física. Se debe mencionar que la estimulación comienza desde el alumbramiento. A continuación, se mencionan los parámetros tomando en cuenta la edad a trabajar en los niños. 
Según Rosada (2016), el niño o niña comprendido en la edad de 3 a 4 años se mueve con facilidad, gusta correr, saltar, sube o baja las escaleras o monta en triciclo. Cognitivamente hablando se entretiene armando puzles, dobla papeles, rasga, le atraen los materiales de colores, ante dificultades busca la manera de dar posibles soluciones. Se propone retos. Se para en un solo pie durante algunos segundos. Atrapa, coge balones. Corre, camina, trota, y salta en varias direcciones. Golpea, lanza balones de forma combinada. Trepa con coordinación.

\section{Desarrollo psicomotor: 3 a 4 años}

Una correcta postura evidencia que el niño o niña mantiene los pies seguros y veloces. Sube las escaleras sin ayuda y con una coordinación correcta. Tiene autonomía al vestirse y cambiarse de ropa. El desarrollo motor grueso en niños de 3 a 4 años debe incluir: mayor habilidad para correr, saltar, lanzar y patear, habilidad para atrapar balones, para pedalear un triciclo, para saltar en un solo pie reiteradas ocasiones, coordinar los pies y brazos.

Es importante mencionar que el desarrollo psicomotor a partir de los tres años se basa en el equilibrio es decir la adaptación a las necesidades de bipedestación y su desplazamiento. Existen 2 tipos de equilibrio la primera es el dinámico que se refiere a la ejecución de diversos movimientos, y la segunda es el equilibrio estático donde el objetivo es buscar la mantención de la postura.

La coordinación al desarrollar la conciencia global permite realizar movimientos estructurados en varios segmentos del cuerpo, a nivel motriz existe buena coordinación de ojo mano, lo que estimula el ámbito cognitivo que posteriormente será el foco de atención, se debe mencionar que el proceso de desarrollo motriz va relacionado directamente con el mismo, dos procesos diferentes pero complementarios.

Se recomienda tener cuidado especial al momento de incorporar materiales o recursos, estos siempre deben estar bajo supervisión y lo más importante explicar que no deben tener contacto con personas desconocidas.

\section{Metodología}

La presente investigación es de carácter descriptivo, con un enfoque cualitativo, basada en revisión de fuentes bibliográficas, que permite analizar la importancia del uso del arenero en el desarrollo de la motricidad gruesa de los niños en edad inicial, para esto se ha realizado un estudio al grupo de 3 a 4 años permitiendo tener una visión del contexto relacionado con la problemática. Este estudio pretende establecer un contraste hacia la hipótesis planteada con el fin de determinar de qué manera la primera variable (arenero un recurso didáctico), guarda relación a la segunda (desarrollo de la motricidad gruesa). 
Se ha dispuesto que la presente investigación tiene un diseño no experimental, ya que no se usó un laboratorio, ni manipulación de variables en un ambiente controlado, en este caso se usa la observación y recolección de información como un medio de comprobación.

El diseño experimental sobrepasa la descripción de los conceptos dentro del contexto que se analiza entre ellos claramente se puede identificar causas de los eventos o fenómenos sociales. Como su propio nombre lo dice trata de explicar o interpretar aquellas condiciones y dar el porqué de sus causas. La finalidad del nivel de investigación explicativa es la direccionalidad en la comprobación de los supuestos planteados en un principio.

En este estudio se han tomado en cuenta como población a maestros y niños de 3 a 4 años de una institución educativa de Ambato.

La técnica empleada fue la observación directa a través de la aplicación de una ficha de observación a estudiantes de la Unidad Educativa Darío Guevara, y la entrevista estructurada a docentes de nivel inicial quienes conforman el grupo de investigación cuyo objetivo es realizar el análisis dentro de un contexto de confidencialidad de la información proporcionada. Para ello se cuenta con el soporte del Currículo Nacional de Educación Inicial 2014 que brinda validez a los instrumentos de evaluación.

Para la observación directa se emplearon fichas de observación en donde se registró si los niños de 3 a 4 años cumplen o no con las actividades necesarias para definir si se evidencia la existencia de motricidad gruesa, el resumen de los resultados se expresa mediante una tabla con las frecuencias.

La tabulación de datos de la entrevista estructurada se hizo a través de un proceso analítico mediante el cual se determinó si la respuesta de los docentes entrevistados es positiva o negativa, con la finalidad de resumir cada respuesta del cuestionario en respuestas dicotómicas; sin embargo, también se transcribe un corto resumen de las respuestas obtenidas durante la jornada.

Para el análisis de resultados se emplea estadística descriptiva, mediante la cual se puede determinar las frecuencias con las que aparecen los datos; otro recurso empleado fue un análisis de Chi - cuadrado para variables dicotómicas y categóricas, en esta última etapa se seleccionó una pregunta de cada variable que guarda relación directa con la temática para determinar si existe una relación entre ellas, con este fin, se empleó la herramienta estadística SPSS.

Cabe resaltar que la muestra de docentes de educación inicial es de 4 personas, mientras que la muestra observada de niños de 3 a 4 años es de 25 estudiantes. Para fines 
estadísticos se transformaron las dos preguntas seleccionadas en categóricas y se hizo una equivalencia de la muestra de docentes a la de estudiantes.

\section{Resultados}

En la siguiente tabla se presenta el resumen de los resultados de la observación directa a los niños de 3 a 4 años en su entorno de clases, el objetivo de este ejercicio fue conocer el nivel de desarrollo de la motricidad gruesa en los niños del nivel inicial.

\section{Tabla 1}

Resultados de la observación directa del desarrollo de motricidad gruesa

\begin{tabular}{|c|c|c|c|c|}
\hline \multirow{2}{*}{$\mathbf{N}^{\circ}$} & \multirow{2}{*}{ Ítems de observación directa } & \multicolumn{3}{|c|}{ Frecuencia (Porcentaje) } \\
\hline & & Sí & No & Total \\
\hline 1 & $\begin{array}{l}\text { El niño/a camina y corre manteniendo el } \\
\text { equilibrio a diferentes distancias. }\end{array}$ & $9(36 \%)$ & $16(64 \%)$ & $25(100 \%)$ \\
\hline 2 & $\begin{array}{l}\text { El niño/a salta en dos pies en sentido vertical y } \\
\text { horizontal en diferentes alturas. }\end{array}$ & $5(20 \%)$ & $20(80 \%)$ & $25(100 \%)$ \\
\hline 3 & $\begin{array}{l}\text { El niño/a salta sobre un pie y sobre el otro de } \\
\text { manera autónoma. }\end{array}$ & $5(20 \%)$ & $20(80 \%)$ & $25(100 \%)$ \\
\hline 4 & $\begin{array}{l}\text { El niño/a cruza obstáculos de diferentes tamaños } \\
\text { alternando los pies y manteniendo el equilibrio } \\
\text { del cuerpo. }\end{array}$ & $6(28 \%)$ & $19(72 \%)$ & $25(100 \%)$ \\
\hline 5 & $\begin{array}{l}\text { El niño/a repta combinando obstáculos y } \\
\text { recorridos. }\end{array}$ & $5(20 \%)$ & $20(80 \%)$ & $25(100 \%)$ \\
\hline 6 & $\begin{array}{l}\text { El niño/a camina corre y salta de un lugar a otro } \\
\text { de manera coordinada a velocidades diferentes y } \\
\text { en superficies planas. }\end{array}$ & $9(36 \%)$ & $16(64 \%)$ & $25(100 \%)$ \\
\hline 7 & El niño/a lanza y atrapa pelotas que rebota. & $10(40 \%)$ & $15(60 \%)$ & $25(100 \%)$ \\
\hline 8 & $\begin{array}{l}\text { El niño/a camina sobre líneas rectas y curvas } \\
\text { manteniendo el control postural. }\end{array}$ & $10(40 \%)$ & $15(60 \%)$ & $25(100 \%)$ \\
\hline 9 & $\begin{array}{l}\text { El niño/a mantiene el control postural en } \\
\text { diferentes posiciones del cuerpo (sentado, de pie, } \\
\text { cunclillas). }\end{array}$ & $11(44 \%)$ & $14(56 \%)$ & $25(100 \%)$ \\
\hline 10 & $\begin{array}{l}\text { El niño/a realiza ejercicios que involucre } \\
\text { movimientos segmentados de partes gruesas del } \\
\text { cuerpo. }\end{array}$ & $8(32 \%)$ & $17(68 \%)$ & $25(100 \%)$ \\
\hline
\end{tabular}

En la tabla 1 de resumen de resultados de observación directa se da a conocer que, en la muestra de niños de 3 a 4 años de la Unidad Educativa visitada para aplicar las fichas de observación, más del $60 \%$ no cumple con los ítems necesarios que evidencie un desarrollo de motricidad gruesa. 


\section{Figura 1}

Nivel de aplicación del desarrollo motriz en actividades básicas para niños de 3 a 4 años

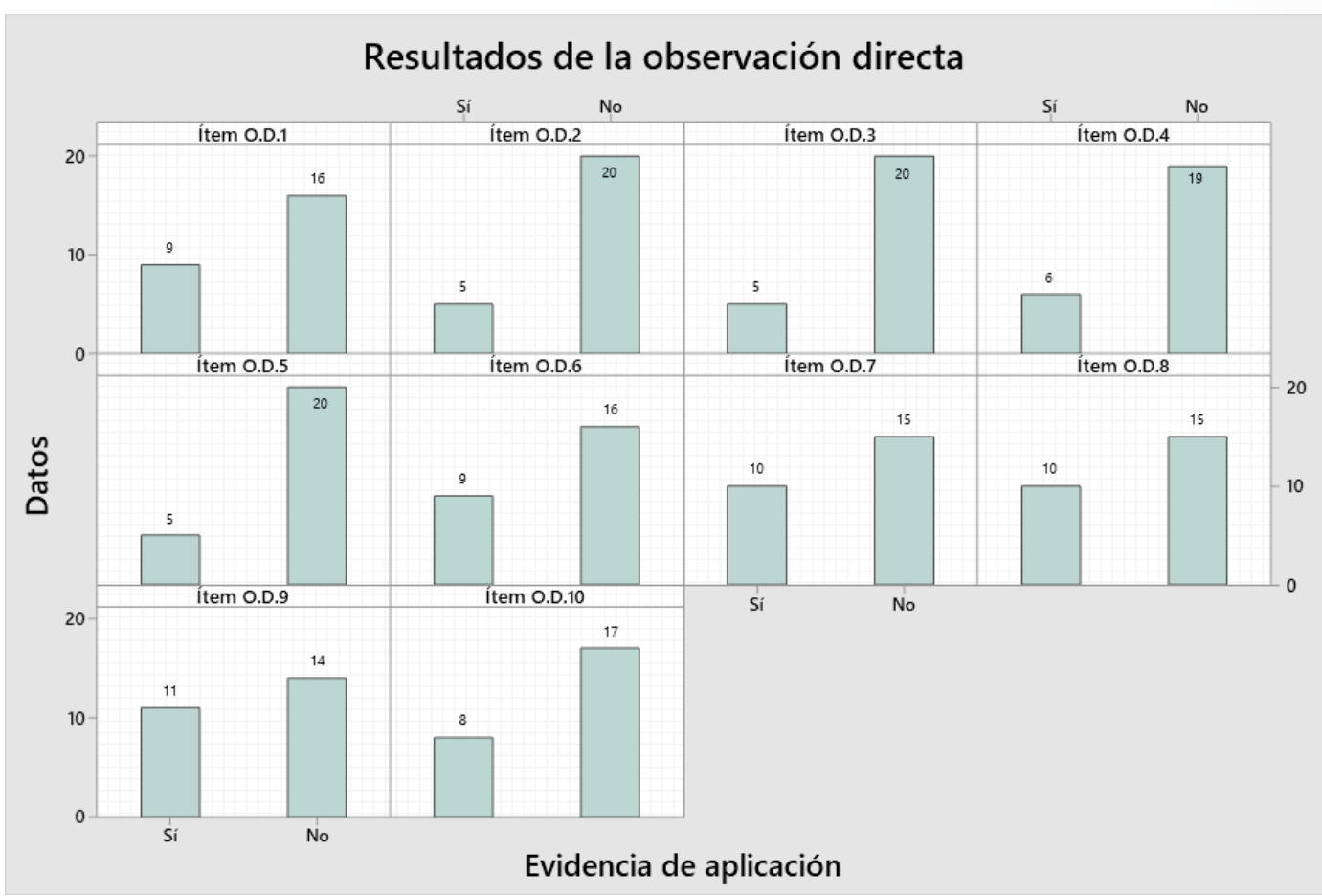

En la figura 1 se muestra gráficamente el nivel de aplicación del desarrollo motriz de los niños de 3 a 4 años en función de los ítems planteados para la observación directa.

Según los datos que se observan en el análisis se determina que la mayoría de los niños no cumplen con el desarrollo de la actividad, la realización de ejercicios que involucre movimientos segmentados de partes gruesas del cuerpo es el eje principal en el desarrollo muscular, debido a que la memoria muscular trabaja a largo plazo y con aprendizajes significativos, los ejercicios estimularán de mejor manera el aspecto motriz de los estudiantes (Gutiérrez 2019).

Por otro lado, se aplicó una entrevista estructurada a los docentes de educación inicial de la Unidad Educativa Darío Guevara quienes imparten sus clases al grupo de estudiantes observados en la primera etapa. Si bien es cierto, el uso del arenero como un recurso didáctico para el desarrollo de la motricidad gruesa no es parte de la planificación curricular que actualmente se aplicó a los estudiantes, los docentes poseen otro tipo de recursos didácticos.

En la tabla 2 se muestran las preguntas estructuradas para la entrevista a los docentes, a su vez, se tabularon sus respuestas en base a las palabras claves del nivel de aplicación del recurso didáctico, el objetivo de la entrevista fue determinar el nivel de conocimiento 
de la importancia del uso del arenero como recurso didáctico para el desarrollo de la motricidad gruesa, por parte de los docentes.

\section{Tabla 1}

Tabulación de respuestas de la encuesta a los docentes de educación inicial

\begin{tabular}{|c|c|c|c|c|}
\hline \multirow{2}{*}{$\mathbf{N}^{\circ}$} & \multirow{2}{*}{ Cuestionario de la entrevista } & \multicolumn{3}{|c|}{ Frecuencia (Porcentaje) } \\
\hline & & Sí & No & Total \\
\hline 1 & ¿Utiliza usted el arenero como recurso didáctico? & $1(25 \%)$ & $3(75 \%)$ & $4(100 \%)$ \\
\hline 2 & $\begin{array}{l}\text { ¿El rincón de arena se debe complementar con } \\
\text { otros recursos tales como: baldes, embudos, } \\
\text { coladores o palas? }\end{array}$ & $2(50 \%)$ & $2(50 \%)$ & $4(100 \%)$ \\
\hline 3 & $\begin{array}{l}\text { ¿Usted ayuda a los niños a reconocer las partes } \\
\text { de su cuerpo a través de actividades lúdicas? }\end{array}$ & $4(100 \%)$ & $0(0 \%)$ & $4(100 \%)$ \\
\hline 4 & $\begin{array}{l}\text { ¿Considera el arenero como recurso didáctico } \\
\text { para el desarrollo de la motricidad gruesa? }\end{array}$ & $1(25 \%)$ & $3(75 \%)$ & $4(100 \%)$ \\
\hline 5 & $\begin{array}{l}\text { ¿El arenero es un rincón para fomentar el trabajo } \\
\text { en grupo? }\end{array}$ & $1(25 \%)$ & $3(75 \%)$ & $4(100 \%)$ \\
\hline 6 & $\begin{array}{l}\text { ¿Considera importante el desarrollo de la } \\
\text { motricidad gruesa a partir del uso del arenero? }\end{array}$ & $4(100 \%)$ & $0(0 \%)$ & $4(100 \%)$ \\
\hline 7 & $\begin{array}{l}\text { ¿Los recursos didácticos deben ser elaborados en } \\
\text { función de los objetivos y previamente } \\
\text { planificados dentro del arenero? }\end{array}$ & $1(25 \%)$ & $3(75 \%)$ & $4(100 \%)$ \\
\hline & $\begin{array}{l}\text { ¿Las actividades lúdicas son la mejor forma para } \\
\text { llegar al aprendizaje? }\end{array}$ & $4(100 \%)$ & $0(0 \%)$ & $4(100 \%)$ \\
\hline 9 & $\begin{array}{l}\text { ¿Los niños/as se relacionan de mejor manera } \\
\text { cuando interactúan en espacios abiertos como el } \\
\text { arenero? }\end{array}$ & $3(75 \%)$ & $1(25 \%)$ & $4(100 \%)$ \\
\hline & $\begin{array}{l}\text { ¿Una buena estimulación favorece al desarrollo } \\
\text { motriz? }\end{array}$ & $4(100 \%)$ & $0(0 \%)$ & $4(100 \%)$ \\
\hline
\end{tabular}

De los resultados de la entrevista se puede determinar que ninguno de los docentes ha aplicado el arenero como recurso didáctico en las actividades lúdicas dirigidas a los niños de 3 a 4 años, sin embargo, también se visualiza que los docentes no conocen acerca de los beneficios y la importancia que tiene la utilización del arenero. 


\section{Figura 1}

Tabulación de las respuestas de la entrevista a los docentes en variables dicotómicas

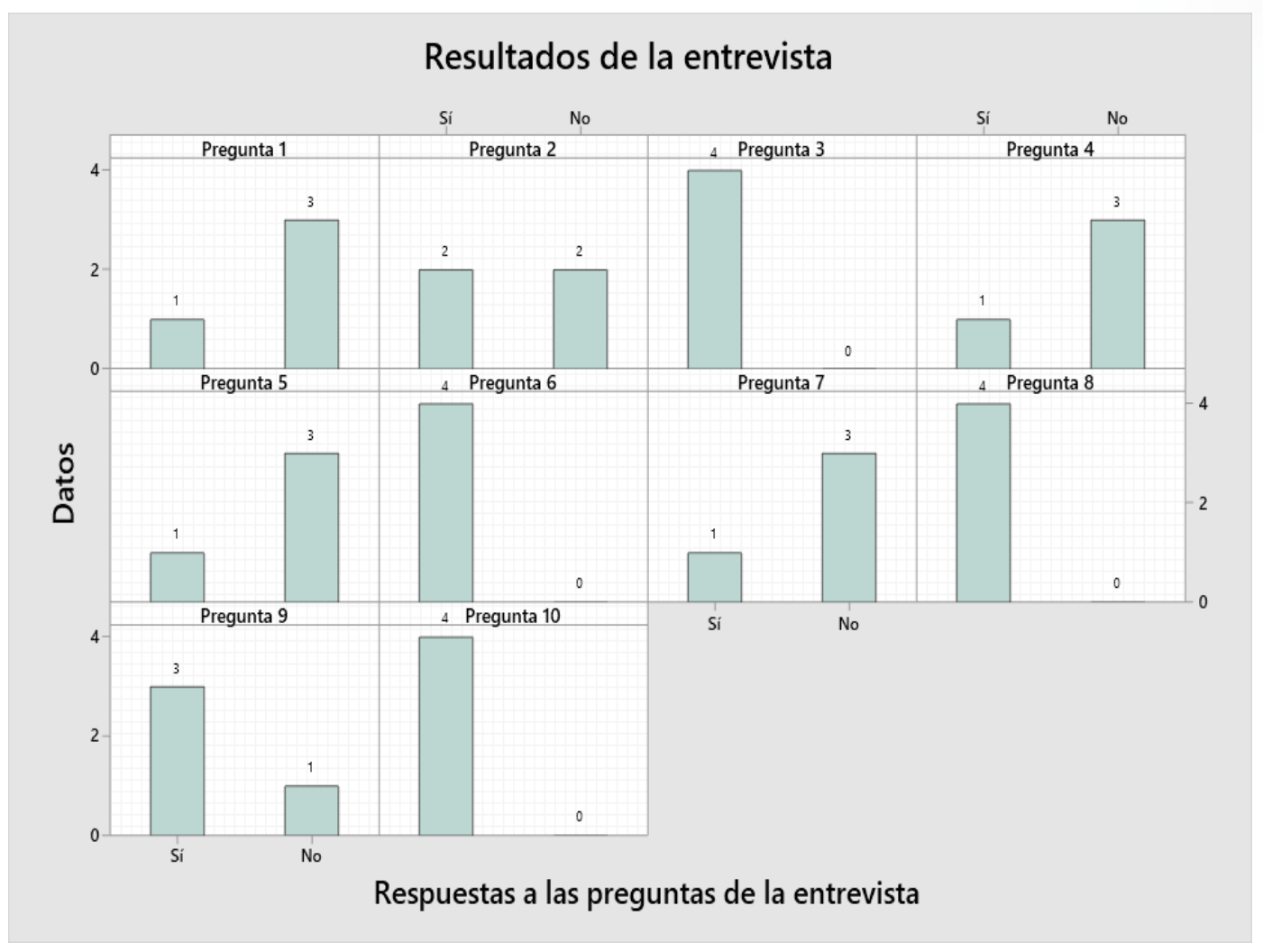

En la figura 2 se muestra de forma gráfica las respuestas a las preguntas de las entrevistas a los docentes, se aprecia que en la pregunta 3, 6, 8 y 10 de la tabla 2, todos los docentes consideran que las actividades lúdicas permiten el desarrollo de la motricidad gruesa, incluyendo la aplicación del arenero; sin embargo, no se ha planificado este recurso didáctico para su implementación dentro de clases.

Luego del análisis descriptivo del estudio de las variables, se selecciona el ítem de observación directa 10 y la pregunta 1 de la entrevista para hacer un análisis de relación entre las variables empleando una tabla cruzada de Chi cuadrado para variables categóricas dicotómicas, con fines estadísticos se hace una equivalencia de la muestra de docentes a la muestra de niños de 3 a 4 años.

En la tabla 3 se muestra el resultado de la tabla cruzada y en la tabla 4 la prueba de Chi cuadrado; los datos se procesaron empleando el software estadístico SPSS. 


\section{Tabla 2}

Tabla cruzada de los resultados del análisis de las dos variables de estudio

\begin{tabular}{|c|c|c|c|c|c|}
\hline & & & \multicolumn{2}{|c|}{$\begin{array}{l}\text { Motricidad gruesa en } \\
\text { los niños }\end{array}$} & \multirow[b]{2}{*}{ Total } \\
\hline & & & No & Sí & \\
\hline \multirow{10}{*}{$\begin{array}{l}\text { Aplica el } \\
\text { arenero como } \\
\text { recurso }\end{array}$} & No & Recuento & 17 & 2 & 19 \\
\hline & & & $89,5 \%$ & $10,5 \%$ & $100,0 \%$ \\
\hline & & recurso & & & \\
\hline & & $\%$ dentro de Motricidad gruesa en los & $100,0 \%$ & $25,0 \%$ & $76,0 \%$ \\
\hline & & niños & & & \\
\hline & & $\%$ del total & $68,0 \%$ & $8,0 \%$ & $76,0 \%$ \\
\hline & Sí & Recuento & 0 & 6 & 6 \\
\hline & & $\begin{array}{l}\% \text { dentro de Aplica el arenero como } \\
\text { recurso }\end{array}$ & $0,0 \%$ & $100,0 \%$ & $100,0 \%$ \\
\hline & & $\begin{array}{l}\% \text { dentro de Motricidad gruesa en los } \\
\text { niños }\end{array}$ & $0,0 \%$ & $75,0 \%$ & $24,0 \%$ \\
\hline & & $\%$ del total & $0,0 \%$ & $24,0 \%$ & $24,0 \%$ \\
\hline \multirow[t]{4}{*}{ Total } & & Recuento & 17 & 8 & 25 \\
\hline & & $\begin{array}{l}\% \text { dentro de Aplica el arenero como } \\
\text { recurso }\end{array}$ & $68,0 \%$ & $32,0 \%$ & $100,0 \%$ \\
\hline & & $\begin{array}{l}\% \text { dentro de Motricidad gruesa en los } \\
\text { niños }\end{array}$ & $100,0 \%$ & $100,0 \%$ & $100,0 \%$ \\
\hline & & $\%$ del total & $68,0 \%$ & $32,0 \%$ & $100,0 \%$ \\
\hline
\end{tabular}

En la tabla cruzada se observa la relación entre los datos de las dos variables, la aplicación del arenero como recurso (aplica: sí / no) y la motricidad gruesa en los niños (existe: sí / no).

\section{Tabla 4}

Prueba de Chi cuadrado de la relación entre las variables de estudio

\begin{tabular}{lccccc}
\hline & & $\begin{array}{c}\text { Significación } \\
\text { asintótica } \\
\text { (bilateral) }\end{array}$ & $\begin{array}{c}\text { Significación } \\
\text { exacta } \\
\text { (bilateral) }\end{array}$ & $\begin{array}{c}\text { Significación } \\
\text { exacta } \\
\text { (unilateral) }\end{array}$ \\
\hline Chi-cuadrado de Pearson & $16,776^{\mathrm{a}}$ & 1 &, 000 & & \\
Corrección de continuidad $^{\mathrm{b}}$ & 12,916 & 1 &, 000 & \\
Razón de verosimilitud & 18,557 & 1 &, 000 & & \\
\hline
\end{tabular}




\section{Tabla 4}

Prueba de Chi cuadrado de la relación entre las variables de estudio (continuación)

\begin{tabular}{|c|c|c|c|c|}
\hline & Valor & $\begin{array}{l}\text { Significación } \\
\text { asintótica } \\
\text { (bilateral) }\end{array}$ & $\begin{array}{r}\text { Significación } \\
\text { exacta (bilateral) }\end{array}$ & $\begin{array}{r}\text { Significación } \\
\text { exacta } \\
\text { (unilateral) }\end{array}$ \\
\hline Prueba exacta de Fisher & & &, 000 &, 000 \\
\hline Asociación lineal por lineal & 16,105 & 1 &, 000 & \\
\hline $\mathrm{N}$ de casos válidos & 25 & & & \\
\hline
\end{tabular}

a. 2 casillas $(50,0 \%)$ han esperado un recuento menor que 5. El recuento mínimo esperado es 1,92 .

b. Sólo se ha calculado para una tabla $2 \times 2$

En la tabla 4 se muestra la prueba de Chi cuadrado para las dos variables, el objetivo del análisis es comprobar si se acepta o rechaza la hipótesis nula del estudio, en este caso, que las variables no están relacionadas, es decir, que la motricidad gruesa en los niños de 3 a 4 años no está relacionada con la aplicación del arenero como recurso didáctico.

Los resultados de la prueba indican una significancia bilateral de 0,000 siendo muy poco probable que la hipótesis nula se cumpla, por lo tanto, se rechaza y se intuye que sí existe una relación entre las variables.

Para el grupo de análisis, existe una relación entre el mínimo desarrollo de motricidad gruesa en los niños de 3 a 4 años y la ausencia de la aplicación del arenero como recurso didáctico. Sin embargo, es necesario avanzar más profundamente con el análisis y verificar los resultados luego de la aplicación del arenero dentro de las actividades lúdicas de aprendizaje en los niños de Educación Inicial.

\section{Conclusiones}

- Es necesaria la elaboración de una guía de actividades para el uso adecuado del arenero ya que se puede desarrollar la motricidad gruesa ya que el niño a través de los movimientos corporales en diferentes espacios estimula el área motora indispensable para fortalecer el equilibrio y conocimiento de su cuerpo y los docentes desconocen el uso de este recurso tan indispensable.

- Es importante realizar actividades lúdicas dentro del arenero puesto q coadyuvan al desarrollo de la motricidad gruesa especialmente en la edad comprendida entre los 3 a 4 años, pues mediante el juego se estimulan diferentes áreas corporales despertando el interés por parte de los niños/as.

- Es necesario que las docentes incorporen en la planificación curricular el uso del rincón del arenero como recurso didáctico a través de diversas actividades donde los niños/as puedan desarrollar su motricidad gruesa de manera innovadora. 


\section{Referencias bibliográficas}

Alpízar, M. \& Alfaro, A. L. (2019). La formación universitaria de docentes de educación primaria: el caso de matemáticas. En Uniciencia (Vol. 33). https://doi.org/10.15359/ru.33-2.8.

Andrade, M. (2015). El Aprestamiento en el Desarrollo de las Funciones Básicas. Riobamba.

Arroba, G. (2018). Los padres permisivos y las normas de convivencia en las aulas en los niños. Ambato: UTA.

Ayoví, C. (2016). El Arenero como Recurso Didáctico para desarrollar la Psicomotricidad. Santo Domingo.

Blanck, M. E. (2016). Nota biográfica em comemoração ao nascimento de Eny Caldeira. Redalyc.

Caizaguano, M. (2015). Los Estilos de Aprendizaje en el Desarrollo de las Funciones Básicas. Riobamba.

Campo, L. (2009). Importancia del desarrollo motor en relación con los procesos evolutivos del lenguaje y la cognición en niños de 3 a 7 años de la ciudad de Barranquilla (Colombia). Barranquilla: Salud Uninorte.

Castelo, A. (2016). Aprendiendo en movimiento en el Desarrollo de las Funciones Básicas. Riobamba.

Cobo, V. (2015). Matrogimnasia, Estímulos, Respuestas, Control, Actividades, Motricidad Gruesa. Ambato: UTA.

Cupuerán, B. (2014). Las Funciones Básicas y su Incidencia en el Desarrollo del Aprendizaje de los niños. Ambato.

Demetrio, L. (2016). Estrategias de aprendizaje emergentes en la modalidad e-learning. RED, 22.

Garza, J. (2014). El Impacto de la Estimulación Temprana en la Primera Infancia. Monterrey.

Guirado, L. (2016). Importancia de la motricidad en el aprendizaje de los contenidos curriculares en el segundo ciclo de Educación Infantil. 
Gutiérrez, V. (2019): El arenero como recurso didáctico para el desarrollo de la motricidad gruesa en los niños de 3-4 años de la unidad educativa "Darío Guevara" de la ciudad de Ambato, Ambato: Universidad Tecnológica Indoamérica, http://repositorio.uti.edu.ec//handle/123456789/1190

Heredia, B. (2015, junio). Filosofía Decroliana. Metodología Decroly.

Infante, R. C. (2016). El método de enseñanza-aprendizaje de trabajo independiente en la clase encuentro: recomendaciones didácticas. Revista de pedagogía.

Inga, G. (2016). Utilización de recursos didácticos para desarrollar el pensamiento creativo de los niños del centro infantil. Riobamba: UNACH.

Lamar, M. (2018). Los Recursos Didácticos mejoran el desarrollo de las Funciones Básicas. Quito.

Little, M. (2016). Too Much Too Soon? An Analysis of the Discourses Used by Policy Advocates in the Debate over Kindergarten. Redalyc, 1-35.

López, N. E. (2014). El sentido de la Educación Sensorial en el pensamiento pedagógico de Ovidio Decroly. Universidad de Antioquía, 1-25.

Medina, N. (2015). Elaboración y Aplicación de un Manual de Estrategias Metodológicas. Riobamba.

Ministerio de Educación. (2014). Currículo de Educación inicial. Quito.

Ministerio de Educación. (2016). Importancia del uso de material didáctico en la Educación Inicial. Quito.

Ministerio de Educación. (2018). Estadísticas Educativas. Quito.

Montenegro. (2016). Estrategias y Metodologías Didácticas. Redalyc, 12.

Muñoz, A. (2016). Las Funciones Básicas y el Desarrollo de la Pre-escritura. Riobamba.

Orellana, K. (2016). El Arenero como Recurso Didáctico para Desarrollar la Psicomotricidad de los Niños. Santo Domingo.

Pazmiño, A. (2015). El Rincón de Arena en la Percepción Táctil. Ambato: UTA.

Pediatric Environmental Health. (2016). Healthy Children. American Academy.

Peña, L. (2015). La Estimulación Temprana como técnica influyente en la adquisición de Funciones Básicas. Quito. 
Pérez, B. (2016). "Influencia de la Estimulación Temprana en el Desarrollo de la Motricidad Gruesa en Niños de 0 A 4 años con Parálisis Cerebral Infantil en la Fundación manos Unidas del Cantón Tisaleo. Ambato: UTA.

Pérez, C. (2015). Los Juegos Tradicionales Infantiles de Persecución y su influencia en el Desarrollo de la Motricidad Gruesa. Ambato.

Pérez, M. (2015). La ludoterapia en el desarrollo motor de los niños de 3 a 5 años con síndrome de Down en la Fundación de niños especiales "San Miguel. Ambato: UTA.

Pinza, G. (2018). Los Recursos Didácticos Mejoran el Desarrollo de las Funciones Básicas. Quito.

Ramos, J. (2015). Funciones Básicas y el Proceso de Lectura. Ambato.

Roa, H. (2016). Estrategias creativas y metacognitivas en el aprendizaje musical. RED, 17.

Rodríguez, R. (2015). Las Funciones Neurocognitivas y su Incidencia en la LectoEscritura. Ambato.

Rosada, S. (2016). Desarrollo de Habilidades de Motricidad Gruesa. La Antigua Guatemala: Universidad Rafael Landívar.

Rosero, E. (2017). El síndrome de Down y el proceso de desarrollo en la motricidad gruesa de niños del inicial II y primero de educación general básica de la Unidad Educativa "Jacques Philippe Binet" sector el Tingo de la ciudad de Quito. Ambato: UTA.

Rosero, J. (2018). Estrategias metodológicas de educación cultural y artística para alcanzar aprendizajes en los niños del cuarto grado de educación general básica. Riobamba: UNACH.

Ruiz, M. (2015). Eficacia de la aplicación de la Guía Portage en la estimulación psicomotriz del niño diagnosticado con retraso en el desarrollo de 3 a 6 años. Quito: UCE.

Sailema, Á. (2018). La actividad física en el desarrollo de la motricidad gruesa de los niños de Segundo año de Educación Básica de la Unidad Educativa Joaquín Lalama. Ambato: UTA.

Sánchez, N. (2016). Aplicación de la estrategia metodológica "Technological Pedagogical Content Knowledge" en el aprendizaje de la física dirigido a los estudiantes del primer año de bachillerato. Riobamba: UNACH. 
Suárez, S. (2017). El Arenero como Recurso Didáctico para el Desarrollo de Percepciones Táctiles en niños de 3 a 4 años. Ambato.

Troya, E. (2015). El Nintendo Wii en el desarrollo de la motricidad gruesa en los niños con síndrome de Down de 3 a 4 años. Ambato: UTA.

UNICEF. (2016). El Grupo del Banco Mundial y UNICEF piden una mayor inversión en el desarrollo en la primera infancia. Washington.

Universidad Rafael Landívar. (2017). Desarrollo de Habilidades de Motricidad Gruesa a través de la Clase de Educación Física para Niños de Primaria. Guatemala.

Ureña, V. R. (2014). Las Funciones Básicas en las Dificultades de Aprendizaje. Memorias III Congreso Internacional Psicología y Educación, 20.

Urquizo, A. (2017). Análisis de la utilización de recursos didácticos en el proceso de enseñanza aprendizaje de la matemática. Riobamba: UNACH.

Valarezo, M. (2016). El arenero como recurso didáctico para desarrollar la psicomotricidad de los niños del nivel inicial. Santo Domingo: Quito UCE.

Valladares, N. (2018). Recursos didácticos en el desarrollo de la atención en el área de matemática en los estudiantes del tercer año. Riobamba: UNACH.

Venegas, J. (2015). La coordinación motriz y su incidencia en el desarrollo de la motricidad gruesa de los estudiantes del décimo año de educación básica. Ambato: UTA.

Yelena, R. (2016). The Reception of John Dewey's Democratic Concept of School in Different Countries of the World. Redalyc, 65-87.

\section{\Ciencia}


El artículo que se publica es de exclusiva responsabilidad de los autores y no necesariamente reflejan el pensamiento de la Revista Conciencia Digital.

\section{Ciencia}

El artículo queda en propiedad de la revista y, por tanto, su publicación parcial y/o total en otro medio tiene que ser autorizado por el director de la Revista Conciencia Digital.
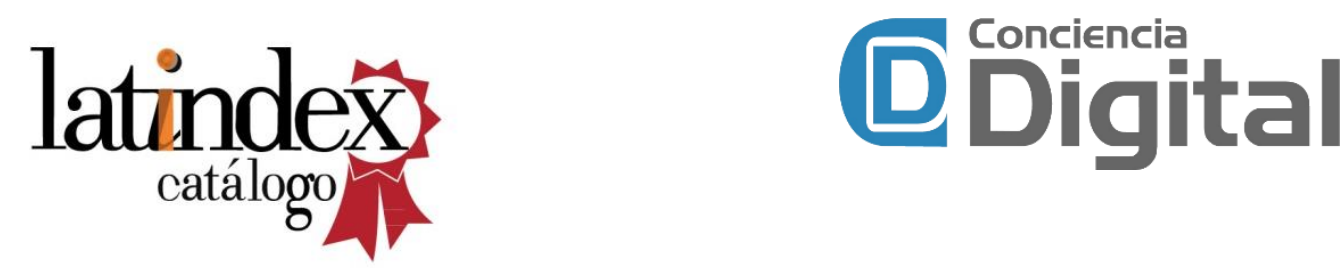

Indexaciones

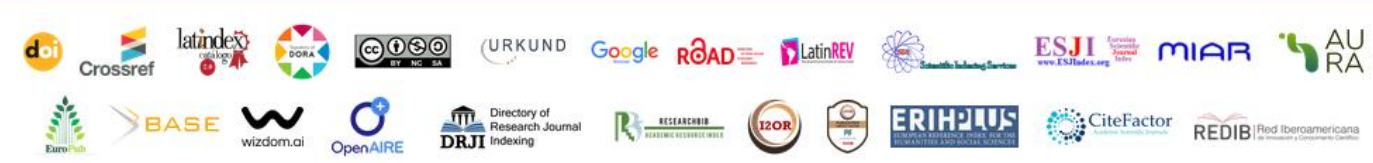

